\title{
COMPLEX THINKING SUPPORTING CARE STRATEGIES FOR THE PREVENTION OF STDS/AIDS IN ADOLESCENCE ${ }^{1}$
}

\author{
Ítalo Rodolfo Silva², Francisca Georgina Macêdo de Sousa ${ }^{3}$, Marcelle Miranda da Silva4, Thiago Privado da \\ Silva ${ }^{5}$, Joséte Luzia Leite 6
}

\begin{abstract}
${ }^{1}$ Part of a thesis - Managing nursing care in complexity - Adolescence in the context of STDs/AIDS, presseted Programa de Pós-Graduação em Enfermagem, Escola de Enfermagem Anna Nery (EEAN), Universidade Federal do Rio de Janeiro (UFRJ) in 2012 which financial support from the Fundação Carlos Chagas Filho de Amparo à Pesquisa do Estado do Rio de Janeiro.

${ }^{2}$ Doctoral Student, Programa de Pós-Graduação em Enfermagem, EEAN/UFRJ. Professor Assistente UFRJ, Campus Macaé. Macaé, Rio de Janeiro, Brazil. E-mail: enf.italo@hotmail.com

${ }^{3}$ Ph.D. in nursing. Adjunct Professor, Universidade Federal do Maranhão. São Luiz, Maranhão, Brazil. E-mail: fgeorginasousa@ hotmail.com

${ }^{4}$ Ph.D. in Nursing. Adjunct Professor, EEAN/ UFRJ. Rio de Janeiro, Rio de Janeiro, Brazil. E-mail:marcellemsufrj@gmail.com

${ }^{5}$ Doctoral Student, Programa de Pós-Graduação em Enfermagem, EEAN/UFRJ. Rio de Janeiro, Rio de Janeiro, Brazil. E-mail:thiagopsilva87@gmail.com

${ }^{6}$ Ph.D. in Nursing. Associate Professor, Programa de Pós-Graduação em Enfermagem, EEAN/UFRJ. CNPq Researcher. Rio de Janeiro, Rio de Janeiro, Brazil. E-mail:joluzia@gmail.com
\end{abstract}

\begin{abstract}
This was qualitative research performed with 15 nursing professionals of a study cohort on adolescent health, in the capital of Rio de Janeiro/Brazil. The objective of the study was to discuss nursing care strategies for the prevention of STDs/AIDS in adolescence, from the perspective of complexity. A semi-structured interview was used for data collection from January to August of 2012. Grounded Theory was used as the methodological framework. The category "Starting points for the nursing care of adolescents in the context of STDs / AIDS" is presented, which discusses aspects related to interdisciplinarity; multidimensionality and specificities of the adolescence-related process, in the midst of vulnerabilities to STDs/AIDS, thereby revealing the importance of contemplating the phenomenon as delimited by its complexity.
\end{abstract}

DESCRIPTORS: Nursing. Adolescent. Sexually transmitted diseases. HIV.

\section{O PENSAMENTO COMPLEXO SUBSIDIANDO ESTRATÉGIAS DE CUIDADOS PARA A PREVENÇÃO DAS DST/AIDS NA ADOLESCÊNCIA}

RESUMO: Pesquisa de abordagem qualitativa, realizada com 15 enfermeiros de um núcleo de estudos da saúde do adolescente, da capital do Rio de Janeiro, Brasil. O objetivo do estudo foi discutir estratégias de cuidados de enfermagem para a prevenção de DST/Aids na adolescência, na perspectiva da complexidade. A entrevista semiestruturada, realizada de janeiro a agosto de 2012, foi empregada como técnica de coleta de dados. A Teoria Fundamentada nos Dados foi utilizada como referencial metodológico. Apresenta-se a categoria: Pontos de partida para o cuidado de enfermagem ao adolescente no contexto das DST/Aids, que discute aspectos relacionados à interdisciplinaridade, multidimensionalidade e especificidades do processo de adolescer em meio às vulnerabilidades para as DST/ Aids, revelando a importância de contemplar o fenômeno delimitado a partir da complexidade existente nele.

DESCRITORES: Enfermagem. Adolescente. Doenças sexualmente transmissíveis. HIV.

\section{EL PENSAMIENTO COMPLEJO SUBSIDIANDO ESTRATEGIAS DE CUIDADO PARA LA PREVENCIÓN DE LAS ITS/SIDA EN LA ADOLESCENCIA}

RESUMEN: Investigación de abordaje cualitativo, realizada con 15 enfermeros de un centro de estudio de la salud de los adolescentes, de la capital de Río de Janeiro/Brasil. El objetivo fue discutir las estrategias de atención de enfermería para la prevención de ITS/SIDA en la adolescencia, desde la perspectiva de la complejidad. La entrevista semiestructurada, realizadas entre enero y agosto de 2012, fue empleada como técnica de recolección de datos. La Teoría Fundamentada de los Datos fue utilizada como marco metodológico. Muestra la categoría: "Los puntos de partida para la atención de enfermería a los adolescentes en el contexto de las ITS/SIDA", que discute los aspectos relacionados con la interdisciplinariedad; multidimensionalidad y especificidades del proceso de entrar en la adolescencia en medio de la vulnerabilidad a las ITS/SIDA, revelando la importancia de contemplar el fenómeno delimitado a partir de la complejidad existente en él.

DESCRIPTORES: Enfermería. Adolescente. Enfermedades de transmisión sexual. VIH. 


\section{INTRODUCTION}

Adolescence is a dynamic process founded by the uniqueness of being an adolescent and the contextual plurality in which it occurs. These characteristics reflect the otherness imbued in the construction of the subject, which happens from connections with others, ${ }^{1}$ and at the same time meets the recursive circuit principle of complexity science $^{2}$ in which man is a product and producer in society, in an interdependent relationship.

Conceiving of the adolescent based oncomplexity means contemplating him/her in his/her multidimensionality. To that end, it is necessary to recognize him/her beyond the mechanistic simplification of a body in physiological, morphological and psychologicaltransition, ${ }^{3}$ but also as a subject that reflects and is reflected by cultural and social aspects.

However, this reality is still challenging to the society, to the health care systems, and consequently to nursing, whereas it differs from the stereotype of adolescence as a crisis phase and generator of conflict. ${ }^{3}$ This characterization exists since the first scientific construct on the subject, which comes with Stanley Hall's Storm and Stress Model in the early twentieth century, which, under the influence of Darwin's Evolutionary Theory, considers adolescence a fundamentally biological process. ${ }^{4}$ Indeed, these parameters corroborate the hegemonic paradigm that focuses on health and disease, or even on human development, as occurs when the beginning and end of adolescence are chronologically predetermined. ${ }^{5}$

From another perspective, the peculiar crises of adolescent growth and development and riskgenerating health behaviors can be understood from the complex thought as vulnerabilities, included as dimensions that connect to adolescent difficulties in recognizing and dealing with the risks and uncertainties of the process of adolescence. In this context is the exercise of sexuality, and with it, the factors that intervene in safer sexual behaviors, namely: unequal relationship of power between genders; ${ }^{6}$ feelings of invulnerability to unsafe sexual practices; ${ }^{7}$ consumption of addictive drugs, among other aspects related to the social, economic and cultural context. . $^{5-6}$

Therefore, the awakening of sexual practice can reflect an adolescent vulnerability to Sexually Transmitted Diseases (STDs), especially the Acquired Immune Deficiency Syndrome (AIDS). ${ }^{6}$ Therefore, when thinking about nursing care for the promotion of sexual health and the prevention of STDs/AIDS in adolescence, the multiple factors that influence adolescent behavior must be considered. Thus, recognizing the complexity involved in the process of adolescence is essential. ${ }^{5}$

Given the above, the question arises: what strategies can support nursing care practices for adolescents for the prevention of STDs/AIDS from a complexity perspective? Thereby, the objective was to discuss nursing care strategies for the prevention of STDs/AIDS in adolescence from the view of Complexity Science.

\section{METHOD}

This was a qualitative study, with Complexity Science as a theoretical background ${ }^{2}$ and Grounded Theory as a methodological framework, a method developed from a set of analytical resources that generated a theoretical matrix when systematically conducted. ${ }^{8}$

The study was performed on a cohort students in adolescent health studies, in a university hospital in the capital of Rio de Janeiro, Brazil. The activities in this scenario include the three health care levels: Primary, Secondary and Tertiary, recommended by the Unified Health System (UHS).

Fifteen nurses participated in the study, composing three sample groups, because the definition of new sample groups is related to the need for explanatory conformation of the phenomena emerging in the analytical course of the data. The main hypothesis that guided the delimitation of the three sample groups was the reciprocal actions of the adolescent process, which are inherent to the adolescent, regardless of the care scenario. Therefore, how do nurses perceive the cross-sectional character of this process at different levels of health care? Thus, the subjects were distributed as follows: six nurses allocated in primary health care composed the first group; five in secondary health care composed the second group; and four in tertiary care were part of the third group.

The subjects were intentionally selected, with theoretical sampling following the Grounded Theory assumptions, which consists of maximizing opportunities for comparing facts, incidents or events to determine how a category varies in terms of its properties and dimensions. ${ }^{8}$

The inclusion criteria were the following: being a nurse caring for adolescents involving 
preventive approaches to STDs/ AIDS. Those who had been performing these activities for less than one year were excluded.

The mean professional experience of the study participants caring for adolescents was 2.5 years. Three had an academic master's degree, whose research subjects involved adolescents/ adolescence and ten had attended or were attending a graduate course specializing in adolescent health, with a residency component.

A semi-structured interview was used as the data collection technique, conducted between January to August of 2012, and recorded using a digital media. Data analysis was performed based on the encoding process, which in Grounded Theory consists of comparative analysis on three levels - open, axial and selective. ${ }^{8}$

In open coding, the concepts are identified from the comparisons between data properties and dimensions. At this stage, there are preliminary codes according to the titles assigned to each incident, idea or event. By having the preliminary codes, the comparison between them allows one to group them into conceptual codes.

In axial coding, there is a grouping of the conceptual codes to form categories and subcategories, ${ }^{8}$ aiming to begin regrouping data that were separated in the open coding, seeking a dense explanation of the phenomenon.

Selective coding consists of the comparison and analysis of categories and subcategories, performed continuously, and it aims to develop categories, integrate and refine the theoretical matrix, giving rise to the central phenomenon. ${ }^{8}$

The categories were ordered according to paradigmatic model, ${ }^{8}$ which gives an interactive coherence among the dimensions that support the investigated phenomenon. It is structured from the following components: phenomenon, causal conditions, intervening conditions, context, action/interaction strategies, and consequences.

The research project was approved by the Ethics Committee in Research at Escola de Enfermagem Anna Nery, Universidade Federal do Rio de Janeiro, protocol n. 082/2011 and by the Ethics Committee at the University Hospital Pedro Ernesto, protocol n. 3149/2011. The researchers met the requirements of Resolution n. 196/96 of the National Health Council. Subject participation was voluntary, after explanation and signing of the Terms of Free and Informed Consent.

\section{RESULTS AND DISCUSSION}

The central phenomenon in the theoretical matrix, developed from constant comparative data analysis, was: "viewing the management of nursing care in complexity-adolescence in the context of STDs/AIDS". However, in this article, the category that is configured as strategic in the paradigmatic scheme will be considered because, in a broad sense, it supports the development of intervention mechanisms from the principles of complexity that constitute the investigated phenomenon itself.

From this perspective, the category, "starting points for the nursing care of adolescents in the context of STDs/AIDS" is presented, supported by the subcategories of "awakening the ability to understand risks and uncertainties of the adolescence process in the adolescent"; "contemplating challenges for interdisciplinary practices for adolescents in the context of STDs/AIDS"; "intervening in the emergence of complexity"; "globally recognizing the adolescent to intervene in his/ her singularities".

\section{Awakening the ability to understand risks and uncertainties of the adolescence process in the adolescent}

Risk and uncertainty are inherent to the human condition, ${ }^{2}$ because of man's inability to grasp the totality of reality. Therefore, they cannot be eliminated from complex systems that permeate mankind, since science itself does not involve precision, but possibilities for approximation of the objective reality. ${ }^{9}$

By resizing these principles to the healthy adolescent development process, especially regarding the exercise of sexuality, one can consider that the uncertainties and risks are exacerbated by the need to know oneself, and especially to know the other as objects of desire and pleasure. However, those needs, associated with feelings of omnipotence, corroborate to strengthen individual vulnerabilities to STDs/AIDS, as pointed out by nurses: [...] he is experiencing the things the world has to offer, this experimentation can become dangerous from the moment he does not care to escape the dangers (E07).

Regarding the adolescents' superhero characteristics, nurses must tell them that superheroes get sick and die (E09). 
Because they think they can do it all, that nothing happens to them because they are superheroes, our role is also to show that things can happen, they have to know that AIDS is there and that it can affect everyone, including them (E06).

Based on the testimonies, it is possible to reinforce the thought that the conditions affecting individual vulnerability are: cognitive, when it comes to information about the phenomenon and ways to face it; behavioral, when it comes to the ability to convert knowledge into protective attitudes about oneself and others; social, because they relate to access to the necessary resources for adoption of protective behaviors. ${ }^{10}$ For these reasons, the vulnerabilities consist of sets of interactions between risks/uncertainties/illusions involving characteristics of the individual, the community and available programs. ${ }^{11}$ Therefore, they cannot be thought of in isolation.

In this context, there is the importance of highlighting the conception of logical complexity ${ }^{2}$ - unitas multiplex, when it states that the organization of phenomena occurs in unit and multiplicity without, however, failing to consider that the multiple does not become singular, nor does the singular become multiple. By applying this principle to the research findings above, one might think that the social, cultural and economic contexts influence adolescent sexual behavior, ${ }^{5}$ by inhibiting or enhancing protective mechanisms for safe sex.

On the other hand, the strategies designed to exercise healthy sexuality should consider not only the contextual influence, but also the uniqueness of being an adolescent in order to favor his/her recognition as the protagonist of self-care. In this regard, the respondents recognized and valued the construction of adolescent autonomy as a resource for the prevention of STDs/AIDS.

Prevention is his choice. So, in every appointment we stress the importance of a condom, but he is the one who decides it, it's his body, he has an autonomy to exercise, but he needs to know it (E01).

[...] We want this adolescent to have autonomy over his health [...] it is necessary not only to charge but also to show that he had the autonomy to act, because during care we see that adolescent inside a cage, and wherever the family puts the cage is whatever he sees in life. Sometimes that adolescent looked, but didn't see, and suddenly, this cage is open and he doesn't know whether he should stay or go, whether he should go and not return, it's a freedom he hasn't had and he can't handle it (E05).
Therefore, the construction and exercise of autonomy are among the strategies listed by the study participants for the prevention of STDs/ AIDS and promotion of the adolescents' sexual health. However, when considering complexity as a system of interactions and adolescence itself as a social phenomenon, ${ }^{3}$ the need is considered for this investment to be extended to other scenarios, such as school and family, ${ }^{5}$ where they can establish together mechanisms of help for the adolescent, in order to understand that health also depends on factors that are intrinsic to the subject. In this particular context, health depends on behaviors adopted considering the risks and uncertainties of unprotected sexual practice.

\section{Contemplating challenges for interdisciplin- ary practices for adolescents in the context of STDs/AIDS}

Although nursing has particular scientific constructs that enable classifying it as an academic discipline and profession, its actions, as well as the actions of other members of the multidisciplinary healthcare team, should be complementary to each other, because all address a common aim, the health and quality of life of those under their care. In this sense, interdisciplinarity in health care provided to the adolescent in the context of STDs/ AIDS prevention emerges as an essential strategy to achieve this aim.

The new demands for health and care require connections between knowledge, skills and attitudes that favor understanding of the individual and the community in a multidimensional perspective, thereby overcoming the mechanistic and isolated actions. In health, interdisciplinarity is an indispensable strategy for healthy human development in its complexity. ${ }^{12}$ Nevertheless, despite interdisciplinarity being conceived only in theory, movements with a view to its consolidation have been encouraged and developed. However, as in any paradigm shift, there are steps that anticipate the concreteness of emerging and, in this sphere, respondents revealed developments that, although starting from multidisciplinary actions, become necessary for interdisciplinary to overcome idealization.

In the ward there is a multidisciplinary meeting where decisions are taken together, this thing of interdisciplinarity works within the ward (E02);

It is necessary that professionals show themselves more, show what they think, what they do. Translating 
this discussion to STDs/AIDS, I believe that it even facilitates it, because with this adolescent, the professional begins to realize that he can't work alone, so this understanding helps (E03).

It's no use having a multidisciplinary environment when we don't have an interdisciplinary environment in which they intercommunicate - and that makes a difference. When attending adolescents, one swallow doesn't mean it is summer [...] no professional category can do it alone. We need to be aware of this interdependence (E08).

Given these statements, it is possible to notice two dimensions influencing interdisciplinary practices, namely: the working environment, favorable to the integration of the thinking/doing of the health care team and the importance attributed to this practice by professionals, mediated by the perception of the need for complementarity of health actions.

With regard to scenarios in which health actions are processed, it should be noted that management of the work process and the organizational culture of the health care institution assume prominent roles for interdisciplinarity to become effective, since one can establish strategies for integrating professionals in this sphere. ${ }^{13} \mathrm{How}-$ ever, simply having programmatic conditions for interaction of the multiprofessional team does not seem to be enough for interdisciplinary practices to be developed, given that interdisciplinary emerges as an attitude based on the desire to contemplate the complexity involved in the work process, in health care actions, in the attitudes of care, as well as the multidimensionality of the other.

In this context, "can-do" is subject to "wantto-do", because it appears that interdisciplinarity is initially conceived in the field of ideas, and thereafter strategies for its implementation are performed, such as mentioned by the following respondents: the interdisciplinary approach today is a story we experience for those with the desire to experience it [...] it's not enough to know its importance, one must want to do it (E11).

As a nurse, the way we find to reconcile the participation of professionals in an interdisciplinary view is day to day. There's no model. Even when you are the team coordinator, you can't make the other one attend, but the issue is to sensitize the individual who in front of you, and that's not easy (E11).

Another factor intervening on interdisciplinary practices, that apparently combines the two aforementioned dimensions, is in the field of understanding the boundaries of exercise of each professional discipline, in addition to skills for teamwork. This reality can be seen in the following excerpt: [...] we have some resistance. We had a case when I attended an adolescent and, when talking about sex, I asked her about her first experience, and she answered that it meant nothing, that she hadn't liked it and that there were other issues related to family life. So, I thought it was important to take the case to the psychologist and when I exposed the situation to that professional I was surprised because she questioned why I was asking the adolescent how she felt, since I was not a psychologist. But how would I not, as a nurse, listen to the patient? I don't understand that! What am I a nurse for? To give injections? To hand out medications? It's difficult! (E09).

Among the challenges to complexity, and hence to interdisciplinarity, is the disruption of thoughts and actions that fragment knowledge through a juxtaposition of knowledge in a misguided logic of power hierarchy., ${ }^{2,14}$ The result of these conceptions extends to the work field in health and, in turn, to the poor quality of care, whereas knowledge is limited to technical actions, since they cannot be combined to constitute a thought capable of considering the human situation in its multidimensionality. ${ }^{2}$

\section{Intervening in the emergence of complexity}

When conceiving of adolescence beyond a chronological process, the nurse will be able to expand strategies to manage nursing care in this clientele, beginning with the parameters that define the beginning of the adolescent process, especially through the assessment of preventive intervention mechanisms. That is because adolescents are distinct from one another, ${ }^{5}$ they relate and react to their developmental factors in a singular way, including when experiencing sexuality, because the questions, wishes and desires are manifested in different times and intensities from one another. ${ }^{15}$

Moreover, one corroborates with understanding that the early awakening to the exercise of sexuality must be considered by the health care team, because of the importance of thinking about interventional strategies that are appropriate to the context of vulnerability of the individual receiving care. The same assertion is pointed out by the respondents, as shown by the following excerpts:

[...] I think that if we can get that reference of the youngest one-and that is actually what the Adolescent Handbook is doing - we can work exactly at the beginning of everything (E03); 
[...] Prevention should not happen only when intercourse starts, it must be worked on from the beginning, when doubts start and he wants to know (E01).

Whereas knowledge conditions being, as well as being conditioning knowledge, there is the conceptual distinction of strategy as a possibility to act in the face of uncertainties and randomness. ${ }^{2}$ From this perspective, the instructions on safe sexual behavior must conform with the adolescents' demands, regardless of the age when demands begin. However, the cultural constructions involving sexuality are sometimes configured in barriers for the adolescent to clearly manifest his doubts and desires about sex. Added to this reality is deficient communication on the subject in several scenarios. ${ }^{5}$

It is therefore desirable that nurses develop relational skills in order to favor the quality of care interactions for the adolescent to freely express and manifest his real needs. Thus, sexual practices, beginning earlier and earlier, can be thought about during interventions made possible by health education in nursing clinical practice, taking into account the individuality of the adolescent, without failing to contemplate the multiple contextual facets in which he is integrated. It is in this context that the next subcategory is introduced.

\section{Globally recognizing the adolescent to intervene in his/her singularities}

Nursing care of the adolescent also involves the pursuit and implementation of strategies for health promotion and prevention of risks and disease complications. ${ }^{5}$ Therefore, it is essential to (re)cognize the reality in which the adolescent is integrated, because from this understanding it is possible to understand the magnitude involved in the interventional demands and priorities.

The development of prevention strategies for STDs/AIDS in adolescence is implied in the need to know the adolescent in his multidimensionality, which implies positioning him in his context of social interactions. ${ }^{3}$ In this regard, respondents demonstrated valuing the importance of family as a matrix of influences capable of reflecting on a healthy adolescence process, especially with regard to the adoption of protective behaviors for his own health.

It's about trying to know a little bit of the adolescent's life, because it's no use telling him that he can't smoke, can't drink, can't have sex without a condom, when he is in a social environment and a family life that does not favor it (E01).
They often seek outt heir parents and they do not want to talk [...] We also see this part of the relationship with parents [...] (E02).

[...] sometimes there is not adequate support from the parents (E07).

The nurse can't have a model and use it to address every adolescent, you have to know this adolescent, see who he is, what he brings to you, so that you know his real needs (E08).

Considering the previous reports, the family is configured as a potential key space for the healthy development of its members, ${ }^{16}$ because among other functions, it is characterized as a mediator between the individual and society, while enabling integration with other social institutions. Therefore, when planning/implementing health promotion and disease prevention strategies for adolescents, the nurse cannot dissociate him from his family background. The nurse must therefore share knowledge and actions with this support network to make health education effective, including towards a healthy exercise of sexuality.

The very understanding of health promotion happens through the process that enhances the individual and collective ability to interfere in conditions related to life and health, thereby ensuring opportunities and resources to provide the guarantee of integrative health for the individual and the collective. The development of actions that reinforce the involvement of families in the living conditions of their members is therefore stimulated, so they can make choices that lead to health, guided by the needs and peculiarities of this social organization. ${ }^{17}$ On the other hand, the development of skills to understand the family as a context that provides and needs care is necessary, because the adolescent's family dynamics establish mechanisms that are either protective of or counterproductive to health. ${ }^{18}$ In this circumstances, the unprotected sexual practices are.

Therefore, the importance of nurse's involving the family when planning strategies aimed at promoting and maintaining the adolescent's health and development is reinforced. Even though Brazilian nursing has stood out with studies that address the family as its research object ${ }^{19}$ in recent years, changes in attitudes of care with these clients do not reflect significant impacts in the same proportions, ${ }^{20}$ especially with regard to relational and subjective skills involved in the care practices of healthy individuals to maintain their health. ${ }^{19}$ Therefore, there is no way to think of the adolescent in his/her multidimensionality without 
considering the influence that the family exerts on the way he/she exists ${ }^{3,5}$ and manifests in the world.

\section{CONCLUSION}

Thinking about adolescence and the STDs/ AIDS issue as complex phenomena enables breaking up the fragmented care practices in health and nursing. When considering the multiple dimensions involved in care systems, in the healthdisease process, and the human condition itself, complexity enables one to conceive of strategies capable of integrating the multiple facets involved in the very object of intervention.

In an amplified form, the study revealed the importance of contemplating the evidenced issue as a phenomenon that differentiates the subject and interventional context as a key strategy for the prevention of STDs/AIDS in adolescence. Therefore, it meets its own strategy of conception from the perspective of complex thinking, namely, an open system that is strengthened from the information coming from the course of action. It may then strengthen public policies for adolescent health, particularly in the context of sexuality, as long as it is possible to establish interventional mechanisms that are able to allow for adolescents to recognize the risks and uncertainties that permeate unsafe sexual practices; for health education at younger and younger ages, recognizing the multidimensionality of each individual; and for the importance of interdisciplinary care for adolescents.

Discussing nursing care strategies for the prevention of STDs/AIDS in adolescents from the conceptions of nurses who care for these clients, especially in a context that is favorable to such practices, could establish a relevant approach to the investigated phenomenon. This could highlight facets of the same reality, which at the same time do not reveal themselves completely to the knowledge of the studied object. Therefore, is important for the consolidation of the research findings that this study is replicated in other settings of care interactions with adolescents, having the adolescent himself among the study participants, because this sample may reveal other angles of knowledge on the strategies proposed in this study.

\section{REFERENCES}

1. Santos EG, Schwab Sadala MG. Alteridade e adolescência: uma contribuição da psicanálise para a educação. Educ Realidade. 2013; 38(2):555-68.
2. Morin E. Ciência com consciência. $13^{\mathrm{a}}$ ed. Rio de Janeiro (RJ): Bertrand; 2010.

3. Matheus TC. Diálogos sobre a adolescência e a ameaça de exclusão dos privilegiados. Psicol USP [online]. 2012 [acesso 2014 Jul 02]; 23(4):721-35. Disponível em: http:// www.scielo.br/scielo.php?script=sci_issuetoc\&pid $=0103656420140001 \& \operatorname{lng}=$ en\&nrm $=$ iso 4 .

4. Santrock JW. Adolescência. $14^{\mathrm{a}} \mathrm{ed}$. Porto Alegre (RS): AMGH/Artmed; 2014.

5. Roehrs H, Maftum A, Zagonel IPS. Adolescence in the perception of primary school teachers. Rev Esc Enferm USP. 2010;44(2):421-8.

6. Uribe AFR, Valderrama L, Sanabria AM, Orcasita L, Vergara T. Descripción de los conocimientos, actitudes, susceptibilidade y autoeficacia frente al VIH/SIDA em um grupo de adolescentes colombianos. Pensamiento Psicol. 2009; 5(12):29-44.

7. Martins CBG, Almeida FM, Alencastro LC, Matos KF, Souza SPS. Sexualidade na adolescência: mitos e tabus. Cienc Enferm [online]. 2012 [acesso 2014 Jul 02]; XVIII(3):25-37. Disponível em: http:/ / www.scielo.cl/ scielo.php?pid=S0717 95532012000300004\&script=sci_arttext

8. Strauss AL, Corbin J. Pesquisa qualitativa: técnicas e procedimentos para o desenvolvimento de teoria fundamentada. $2^{\mathrm{a}}$ ed. Porto Alegre (RS): Artmed; 2008.

9. Mariotti H. Pensando diferente - para lidar com a complexidade, com a incerteza, com a ilusão. São Paulo (SP): Atlas; 2010.

10. Nader SS, Gerhardt CR, Nader PJH; Pereira DN. Juventude e AIDS: conhecimento entre os adolescentes de uma escola pública em Canoas, RS. Rev AMRIGS. 2009;53(4):374-81.

11. Brêtas JRS. Vulnerabilidade e adolescência. Rev Bras Enferm Ped. 2010; 10(2):89-96.

12. Barra CMCM. Interdisciplinaridade: desafios para a pesquisa e publicação. Fisioter Mov [online]. 2013 [acesso 2015 Jan 02]; 26(4):711-2. Disponível em: http:/ / www.scielo.br/scielo.php?pid=S010351502013000400001\&script=sci_arttext.

13. Carvalho MC, Rocha LFS, Marziale MHP, Gabriel CS, Bernardes A. Work values and practices which characterize the organizational culture of a public hospital. Texto Contexto Enferm [online]. 2013 [acesso 2015 Jan 02]; 22(3):746-43. Disponível em: http:// www.scielo.br/scielo.php?pid=S010407072013000300022\&script $=$ sci_arttext

14. Bispo EPF, Tavares CHF, Tomaz JMT. Interdisciplinaridade no ensino em saúde: o olhar do preceptor na Saúde da Família. Interface [online]. 2014 [acesso 2015 Jan 02]; 18(19). Disponível em: http://www.scielo.br/scielo.php?pi$\mathrm{d}=$ S1414-32832014000200337\&script=sci_arttext.

15. Brêtas JRS, Ohara CVS, Jardim DP, Aguiar Júnior W, Oliveira JR. Aspectos da sexualidade na adolescência. Ciênc Saúde Coletiva. 2011; 16(7):3221-8. 
16. Barbosa DC, Sousa FGM, Silva ACO, Silva ÍR, Silva DCM, Silva TP. Funcionalidade de famílias de mães cuidadoras de filhos com condição crônica. Cienc Cuid Saud. 2011; 10(4):731-8.

17. Brusamello T, Maftum MA, Mazza VA, Silva AG, Silva TL, Oliveira VC. Papel da família e da escola na prevenção do uso de drogas pelo adolescente estudante. Cienc Cuid Saud. 2010;9(4):766-73.

18. Bernardy CCF, Oliveira MLF. The role of family relationships in the initiation of street drug abuse by institutionalized youths. Rev Esc Enferm USP. 2010; 44(1):11-7.

19. Ângelo M, Bousso RS, Rossato LM, Damião EBC, Silveira O, Castilho AMCM, Rocha MCP. Family as an analysis category and research field in nursing. Rev Esc Enferm USP. 2009; 43(2)1337-41.

20. Pinto JP, Ribeiro CA, Pettengill MM, Baleiro MMFG. Cuidado centrado na família e sua aplicação na enfermagem pediátrica. Rev Bras Enferm. 2010; 63(1):132-5. 